\title{
A TEST OF CONNECTIVE TISSUE STATE AND REACTIVITY IN COLLAGEN DISEASES *
}

\author{
By DANIEL M. LASKIN, MILTON B. ENGEL, NORMAN R. JOSEPH AND \\ VICTOR E. POLLAK $\dagger$ \\ (From the Colleges of Dentistry, Pharmacy and Medicine, University of Illinois, \\ Chicago, Ill.)
}

(Submitted for publication January 12, 1961 ; accepted August 17, 1961)

In the group of conditions known as "collagen diseases" there are often morphological changes in discrete areas of the connective tissue. For example, fibrinoid degeneration of the collagen fibers and changes in the ground substance may be seen in the subcutaneous nodules of rheumatoid arthritis and in the skin lesions of lupus erythematosus. These lesions are not well understood. The more generalized alterations in the connective tissue are even more difficult to demonstrate and remain poorly defined. Using an in vivo electrometric method, we have previously determined certain physicochemical properties of normal mammalian connective tissue which are related to its amphoteric colloidal structure (1-5). Since these properties may be altered in pathological states, we have adapted this method to study some of the fundamental connective tissue changes in collagen diseases of humans.

Based upon histochemical, physicochemical and morphological studies, a unified concept of the organization of the extracellular part of normal connective tissue has been developed (6-11). The ground substance has been characterized physicochemically as a two-phase system containing heterogeneous (soluble and insoluble) colloids, electrolytes and water. A water-rich phase containing the soluble components is considered to be in equilibrium with a colloid-rich phase. The existence of these phases at a submicroscopic level has been demonstrated with the electron microscope. The water-rich phase consists of vacuoles with diameters ranging from 600 to 1,200 Ångstrom units (7-10). These vacuoles are enclosed by a much denser colloid-rich phase. Under physiological conditions the amphoteric colloidal matrix

\footnotetext{
* This work was supported in part by a grant from the Graduate Research Board, University of Illinois.

$\dagger$ Established Investigator, American Heart Association, supported by the Illinois Heart Association.
}

bears a net negative charge; this is distributed between the two phases. The colloidal charge governs the distribution of mobile cations and anions through thermodynamic and electrostatic equilibrium and through the chemical binding of ions to the matrix. Electrolyte concentrations and water content in connective tissues are thus determined by the colloidal structure (1-5).

Collagen, glycoproteins and mucopolysaccharides, including chondroitin sulfate and hyaluronic acid, have been conceived to be constituents of a complex coacervate in the matrix of dermal connective tissue (12). The isoelectric point of the matrix ranges from about $\mathrm{pH} 2.2$ to 2.5 depending on its composition. The low isoelectric point is a result of the acidic character of substances such as chondroitin sulfate and other mucopolysaccharides. The density of negative charge of the colloidal matrix is related to the number of titratable groups which bind hydrogen ions between $\mathrm{pH} 7.4$ (physiological) and the isoelectric point ( $\mathrm{pH} 2.2$ to 2.5 ). This depends on the compostion of the matrix with respect to all the colloidal components. That these form complex insoluble aggregates may be inferred from the difficulties usually encountered in attempts to isolate the colloidal components in pure form.

When the enzyme hyaluronidase is injected into the dermis, hyaluronic acid and some of the chondroitin sulfate are disaggregated. This leads to measurable changes in spreading properties and to a lowering of the negative charge density (13-16). The effect may be explained by: 1) removal of negatively charged components, such as hyaluronic acid and chondroitin sulfate $A$, accompanied by 2 ) redistribution of water and electrolytes within the region of spreading. By the action of the enzyme, the normal balance between soluble and insoluble colloidal components is disturbed, and the remaining insoluble colloids are characterized by 
a low density of negative charge. In animal experiments, the effect of hyaluronidase applied subcutaneously is to lower the negative colloidal charge to less than half the initial level (14). The initial state, as indicated by the negative charge density, may be compared with a hyaluronidasemodified state produced during a standard time interval. After the colloidal charge density becomes minimal the subsequent recovery curve, observed electrometrically, illustrates the functional state of the connective tissue (14-16). The serial electrometric evaluation of colloidal charge offers a means of comparing normal and pathological tissues and the effects of various treatments.

\section{THEORETICAL}

At an equilibrium boundary between a charged colloidal surface and an isotonic saline solution there is a difference of potential which depends on the density of colloidal charge and on the composition of the applied electrolyte solution $(5,17$, 18). This is the normal Donnan potential, $E_{D}$, which is related to the Donnan ratio, $r$, by the formula :

$$
E_{D}=\frac{2.303 R T}{96,500} \log _{10} r
$$

where 2.303 is the conversion factor between common and natural logarithms, $R$ is the gas constant in joules per degree, $T$ is the absolute temperature, and 96,500 is the value of the Faraday constant in coulombs. $E_{D}$ is usually not determined directly in tissues; it is measured indirectly by the potential at the surface after substitution of $0.015 \mathrm{M}$ $\mathrm{NaCl}$ at the boundary $(5,17)$. This yields a displaced Donnan potential, $E_{D}{ }^{\prime}$, related to the following quantities: the Donnan potential, the Donnan ratio, the fractions of current transported by anions and cations, and the density of negative colloidal charge, $x(5,17,18)$. Thus

$$
E_{D}{ }^{\prime}-E_{D}=\frac{2.303 R T}{96,500}\left(n_{1}{ }^{\prime}-n_{2}{ }^{\prime}\right)
$$

where $n_{1}^{\prime}$ and $n_{2}{ }^{\prime}$ denote the fractions of current carried respectively by cations and anions in the colloidal phase. The difference is related to the Donnan ratio, $r$, by the formula:

$$
n_{1}^{\prime}-n_{2}^{\prime}=\frac{r^{2}-1.52}{r^{2}+1.52}
$$

where 1.52 is the ratio of the ionic conductance of chloride to that of sodium $(5,17)$. The density of negative colloidal charge, $x$, in equivalents $(\mathrm{Eq})$ per kilogram water is related to $r$ by the formula

$$
x=0.15(r-1 / r)
$$

where $r=\frac{\left(\mathrm{Na}^{+}\right)_{2}}{\left(\mathrm{Na}^{+}\right)_{1}}=\frac{\left(\mathrm{Cl}^{-}\right)_{1}}{\left(\mathrm{Cl}^{-}\right)_{2}}$. The subscripts 1 and 2 refer to the solution phase $(0.15 \mathrm{M})$, and the colloidal phase, respectively. Graphical methods have been described to estimate $x$, the colloidal charge, from $\left(E_{D}{ }^{\prime}-E_{D}\right)$ at any $\mathrm{pH}(5)$. At $\mathrm{pH} 7.4$ and $37^{\circ} \mathrm{C}$, for values of $x$ less than about $0.06 \mathrm{Eq}$ per $\mathrm{kg}$ water, there is a simple linear relation:

$$
E_{d}=-12.3+206 x
$$

where $E_{d}$ denotes the difference $\left(E_{D}{ }^{\prime}-E_{D}\right)$, and is termed the "dilution potential." On the basis of this method, titration curves of numerous colloidal surfaces have been measured. These include dermis, cartilage and epidermis in vivo, and wool surfaces in vitro $(5,17,18)$.

\section{MATERIAL AND METHODS}

The connective tissue function test was performed in 10 healthy persons and in 14 untreated patients with various connective tissue diseases. The age and sex distributions of the two groups are given in Table I. The following pathological conditions were studied: rheumatoid arthritis ( 3 cases), systemic lupus erythematosus ( 3 cases), and scleroderma ( 8 cases). In addition, the alteration in connective tissue was also investigated in 3 patients with Cushing's syndrome. A number of patients in each group was retested after periods of treatment.

Displaced Donnan potentials in dermal connective tissue were measured by a modification of the method previously described for animal studies $(5,14-16)$. Details of the method are as follows: a 25 gauge platinum needle with a glass hub was inserted into the dermis on the anterior surface of the right forearm. ${ }^{1}$ The reference

${ }^{1}$ In human subjects the use of a platinum needle is preferable to surgical exposure of the dermis and direct application of the solutions. In experiments with rats and rabbits the dilution potential in the dermis has been found to be about $-2 \mathrm{mv}$ after direct exposure of the tissue to the dilute solution (5). The same result has been found in a series of animals and humans using the platinum needle technique. In both series of experiments the calculated value of $x$ is about $0.050 \mathrm{Eq}$. Since the platinum needle is filled with saline solution, the metal is at constant potential. Contact with the solution is made by means of saturated $\mathrm{KCl}$, and there is no 
TABLE I

Electrometric results in normal subjects and in patients with connective tissue diseases *

\begin{tabular}{|c|c|c|c|c|c|c|c|}
\hline Condition & Male & Female & Age range & $\begin{array}{l}\text { Baseline dilution } \\
\text { potential }\left(E_{d^{0}}\right)\end{array}$ & $\underset{\text { potential }}{\text { Minimum dilution }}$ & $k$ & $\begin{array}{l}\text { Half-recovery } \\
\text { time }\end{array}$ \\
\hline & & & yrs & $m v$ & $m v$ & & $\min$ \\
\hline $\begin{array}{l}\text { Normal } \\
\text { subjects }\end{array}$ & 5 & 5 & $22-76$ & $-1.9 \pm$ & $-7.9 \pm$ & $\begin{array}{r}0.0021 \\
\pm 0.0006\end{array}$ & $156 \pm 40$ \\
\hline $\begin{array}{l}\text { Rheumatoid } \\
\text { arthritis }\end{array}$ & 0 & 3 & $40-47$ & $\begin{array}{l}-9.1 \\
(-8.0 \text { to }-10.1)\end{array}$ & $\begin{array}{l}-12.3 \\
(-12.0 \text { to }-12.5)\end{array}$ & 0.0000 & No recovery \\
\hline $\begin{array}{l}\text { Lupus } \\
\text { erythematosus }\end{array}$ & 1 & 2 & $14-45$ & $\begin{array}{l}-4.9 \\
-(4.4 \text { to }-5.2)\end{array}$ & $(-11.1$ & 0.0000 & No recovery \\
\hline Scleroderma & 0 & 8 & $28-63$ & $-9.6 \pm$ & $-12.1 \pm$ & 0.0000 & No recovery \\
\hline $\begin{array}{l}\text { Cushing's } \\
\text { syndrome }\end{array}$ & 1 & 2 & $20-35$ & $\begin{array}{l}-5.7 \\
(-5.5 \text { to }-6.0)\end{array}$ & $\begin{array}{l}-11.3 \\
(-10.8 \text { to }-11.7)\end{array}$ & 0.0047 & 65 \\
\hline
\end{tabular}

* Mean values ( \pm standard deviations where stated). Dilution potentials $\left(E_{d}\right)$ can be converted to negative charge density $(x)$ by the formula $E_{d}=-12.3+206 x$.

$\dagger$ The lowest value of $E_{d}$ obtained after the injection of hyaluronidase into the dermis.

junction was made by immersing several fingers of the left hand in a beaker containing $0.15 \mathrm{M} \mathrm{NaCl}$ (Figure 1). The lumen of the platinum needle was filled with 0.1 to $0.2 \mathrm{ml}$ of sterile buffered $(\mathrm{pH} 7.4) 0.15 \mathrm{M} \mathrm{NaCl}$ (solution I), making contact with the dermal connective tissue. The solution was prepared by mixing $10 \mathrm{ml}$ of $0.075 \mathrm{M} \mathrm{Na}_{2} \mathrm{HPO}_{4}$ with $1 \mathrm{ml} 0.15 \mathrm{M} \mathrm{NaH}_{2} \mathrm{PO}_{4}$, and diluting to $110 \mathrm{ml}$ with $0.15 \mathrm{M} \mathrm{NaCl}$. The solutions at the experimental junction and in the reference beaker were each connected to saturated $\mathrm{KCl}$-calomel half-cells by means of saturated $\mathrm{KCl}$ salt bridges. The ends of the connecting tubes were sealed with small tapered glass tubes filled with saturated $\mathrm{KCl}$ in solidified agar. A similar method of studying epidermis has been described (17). Potentials were measured with a Leeds-Northrup type $\mathrm{K}-2$ potentiometer and a galvanometer sensitive to $0.1 \mathrm{mv}$. The circuit is represented as follows:

$\mathrm{Hg}\left|\mathrm{Hg}_{2} \mathrm{Cl}_{2}\right| \mathrm{KCl}$ (sat.) | solution I or II $\mid$ dermis $\mid$
finger $\mid$ solution I $\mid \mathrm{KCl}$ (sat.) $\left|\mathrm{Hg}_{2} \mathrm{Cl}_{2}\right| \mathrm{Hg}$

An initial potential $\left(E_{1}\right)$ between the experimental (forearm dermis) and reference (finger) sites was determined with solution I (buffered isotonic $\mathrm{NaCl}$ ) at the experimental junction. The solution was then aspirated and replaced by 0.1 to $0.2 \mathrm{ml}$ of a $1 / 10$ dilution $(0.015 \mathrm{M}$

metallic contact with the platinum. For these reasons the flow of current is entirely through the solutions. The system may therefore be treated by the same theoretical and mathematical methods that have been applied to wool, epidermis, and to surgically exposed tissue surfaces $(5,17,18)$. In most subjects, the magnitude of the potential $E_{1}$ was about 40 to $50 \mathrm{mv}$, with the experimental (forearm) junction positive with respect to the reference (finger) junction. The sign of the potential always refers to the experimental site.
$\mathrm{NaCl}$, solution II). The displaced potential $\left(E_{2}\right)$ was measured. The initial potential was then re-established with solution I at the experimental site. Each value was based on the mean of two consecutive readings taken over a period of 2 to 3 minutes. The mean value of $\left(E_{2}-E_{1}\right)$ measured before the action of hyaluronidase is denoted as the initial dilution potential, $E_{d}{ }^{0}$. The potentials $E_{1}$ and $E_{2}$ were generally quite constant and reproducible. The values of $E_{1}$ preceding the measurement of $E_{2}$ generally agreed to within $0.5 \mathrm{mv}$. Two values of $E_{1}$ following the measurement of $E_{2}$ agreed equally well (Table II). Standard deviations of four readings were

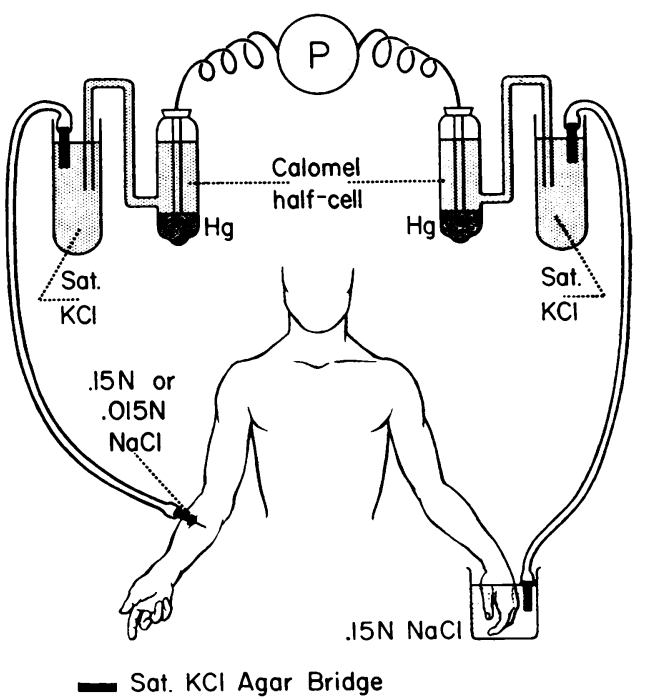

Fig. 1. Diagram of the apparatus USED for the ELECTROMETRIC DETERMINATION OF DISPLACED DONNAN. POTENTIALS IN THE DERMIS. 
about 0.3 to $0.5 \mathrm{mv}$ compared with $E_{d}$ values of about $-2 \mathrm{mv}$ (normal), and $-8 \mathrm{mv}$ (normal plus hyaluronidase).

Immediately after determination of $E_{d}^{0}, 15$ turbidity reducing units of testicular hyaluronidase (Wyeth),

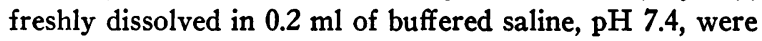
injected into the test site with a 29 gauge needle inserted into the lumen of the platinum needle. Dilution potentials were measured at intervals of 15 and 30 minutes, and at 1, 2, 3 and 4 hours after injection, unless halfrecovery occurred more rapidly. Control experiments were made over similar time intervals using a $0.15 \mathrm{M}$ $\mathrm{NaCl}$ solution which contained no enzyme. In healthy subjects, these showed no appreciable change of potential over periods of 1 to 2 hours. From the dilution potential, $E_{d}$, the negative colloidal charge density, $x$, of the dermal connective tissue may be calculated according to Equation 5. The values of $x$ may thus be followed in relation to time after the action of the enzyme.

\section{RESULTS}

Normal subjects. In a typical experiment on healthy young adults, the initial value of the dilu- tion potential was about $-2 \mathrm{mv}$. This represents a colloidal charge of about $0.05 \mathrm{Eq}$ per $\mathrm{kg}$ tissue water, corresponding closely to that found for normal dermal connective tissue of rats and rabbits (5). After the action of testicular hyaluronidase the dilution potential fell to about $-8 \mathrm{mv}$ on the average, corresponding to a negative colloidal charge of about $0.02 \mathrm{Eq}$, about 40 per cent of the normal level. This level was observed after 15 to 30 minutes' exposure to the enzyme. Readings of $E_{1}$ and $E_{2}$ before and after hyaluronidase are given for a healthy subject and a patient (Table II). After the period of exposure, serial readings were made, and were found to increase during half-hour or 1-hour intervals. Half-recovery for healthy subjects was found to occur between 2 and 3 hours after the minimal potential of $-8 \mathrm{mv}$ had been observed. For a subject showing an initial value of colloidal charge of $0.05 \mathrm{Eq}$ and a minimal value of $0.02 \mathrm{Eq}$, half-recovery would correspond

TABLE II

Initial and displaced potentials* of a healthy subject compared with those of scleroderma patient

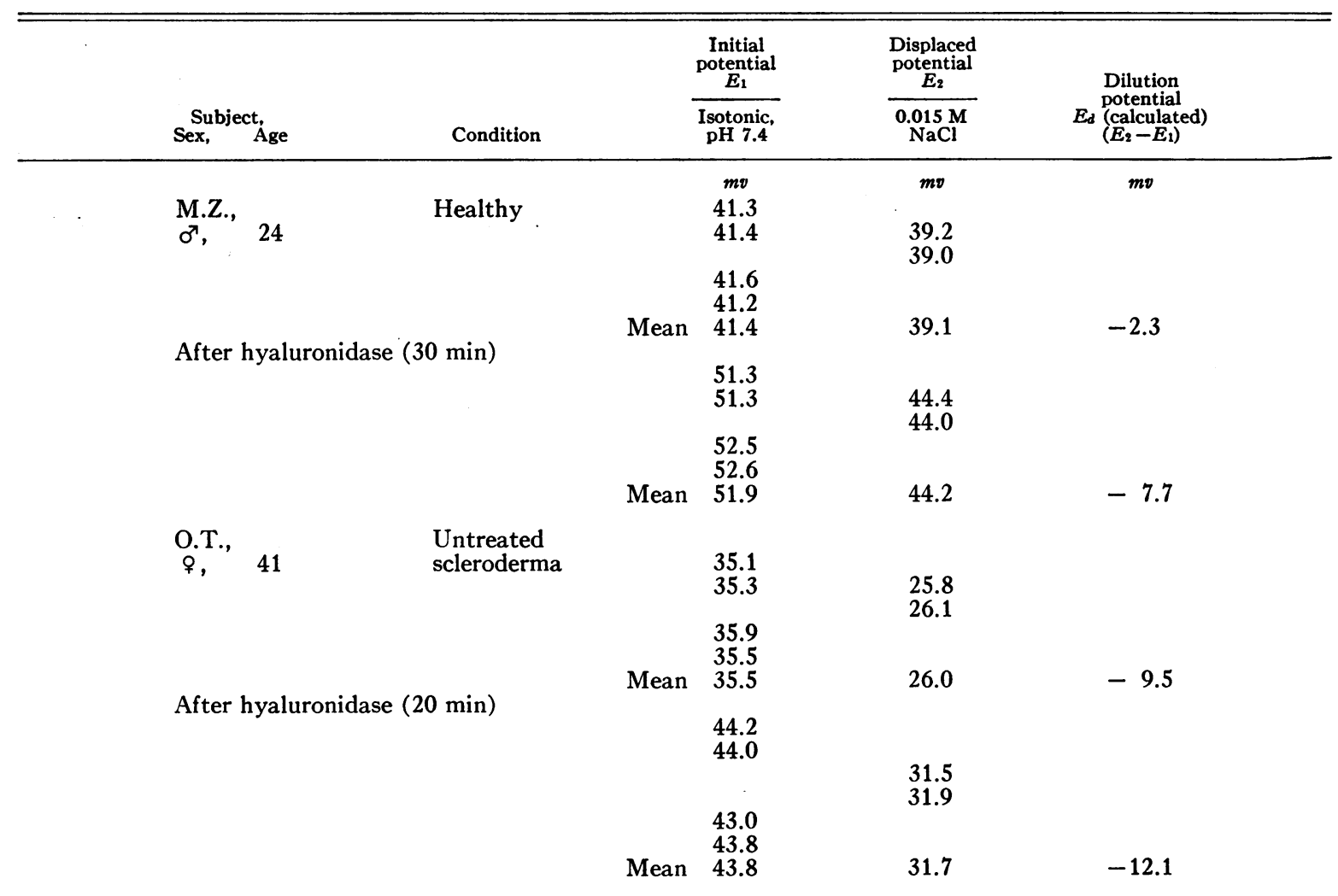

* Sign of potentials $E_{1}$ and $E_{2}$ was always positive, i.e., dermal connective tissue positive with respect to finger epidermis. Dilution potentials were calculated from the average values of $E_{1}$ and $E_{2}$. Each reading of $E_{1}$ and $E_{2}$ refers to a different isotonic or dilute solution. 


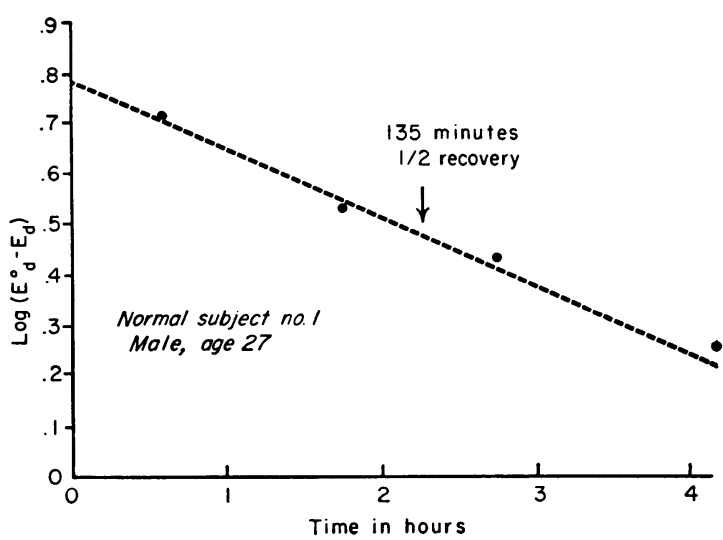

Fig. 2. Logarith Mic RECOVERY CURVE FOR A NORMAL SUBJECT.

to a value of $0.035 \mathrm{Eq}$, or to a dilution potential of $-5 \mathrm{mv}$. In the control series, potentials were observed over a period of 3 to 4 hours after the minimal potentials had been observed. In every case half-recovery had occurred within that time. The average half-recovery period for 10 normal subjects was found to be 156 minutes (Table I).

On the basis of animal experiments it has been found that recovery of colloidal charge after the action of hyaluronidase follows a logarithmic equation (16). It follows that half-recovery times may be conveniently estimated from a small number of serial measurements of dilution potential (Figure 2 ). It is assumed that at any time $t$ after the removal of the enzyme, the rate of recovery is proportional to the displacement of $x$ from the initial value, $x^{0}$. This is represented by the formula $(15,16)$ :

$$
d x / d t=a\left(x^{0}-x\right)
$$

where $a$ is a rate constant expressed in reciprocal minutes. By integration

$$
\ln \left(x^{0}-x\right)=-a t+C
$$

where $C$ is the integration constant, and $\ln$ is the natural logarithm. By applying Equation 5, the equation for $E_{d}$ as a function of time is obtained:

$$
\ln \left(E_{a}{ }^{0}-E_{d}\right)=-a t+B
$$

\footnotetext{
${ }^{2}$ Equation 8 is used empirically to give a convenient means of estimating half-recovery times. A more exact check of the validity of the equation would require experimental data extending over more than one logarithmic decade. Since the potentials all fall between -2 and -12 $\mathrm{mv}$, it is not possible to check the formula beyond these limits.
}

where the constant $B$ is obtained from the maximum displacement $\left(E_{d}{ }^{0}-E_{d}\right)$ at zero time (beginning of recovery). In the computations it is convenient to use common rather than natural logarithms. Then

$\log _{10}\left(E_{d}^{0}-E_{d}\right)=-k t+\log _{10}\left(E_{d}^{0}-E_{d}^{\prime}\right)$ [9]

where $E_{d}$ is the dilution potential at time $t, E_{d}{ }^{0}$ is the value before use of hyaluronidase, $E_{d}{ }^{\prime}$ is the value of the maximally displaced dilution potential at zero time, and $k$ is a rate constant expressed in reciprocal minutes. The relation between $k$ and $a$ is : $a=2.303 k$, where 2.303 is the conversion factor between common and natural logarithms. Equation 9 has been found to give an adequate description of the data in a large number of animal experiments $(15,16)$. Half-recovery time and the rate constant, $k$, are related by the formula : $\mathrm{t}_{1}=0.301 / k$, where 0.301 is the logarithm of 2 , and $t_{1}$ is the half-recovery time. From the data for 10 healthy subjects, values of $k$ and $t_{1}$ were calculated. This requires values of $E_{a}{ }^{0}, E_{d}{ }^{\prime}$ and of the serial dilution potentials $E_{d}$ as a function of time after maximal enzyme effect. The mean halfrecovery time (Table I) agrees well with that estimated from the normal time-response curve shown in Figure 2.

Connective tissue diseases. In patients with connective tissue diseases, the negative charge density, $x$, of the dermal colloids was about 30 to 60 per cent lower than that found in healthy subjects. The mean value was approximately $35 \mathrm{mEq}$ in

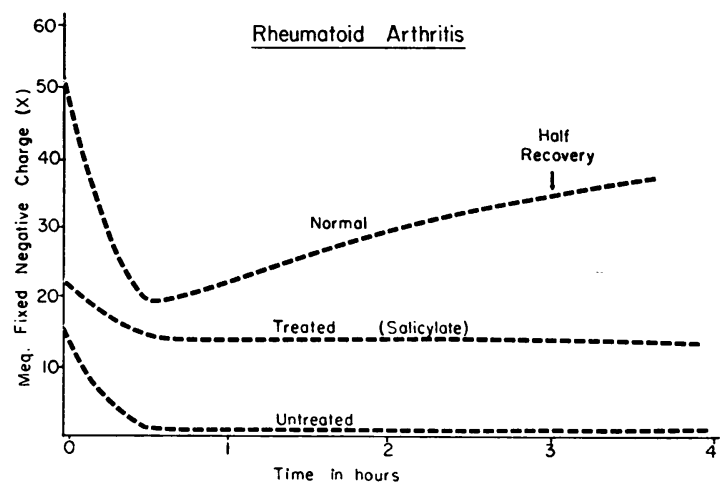

Fig. 3. Mean time-Response CURVE for healthy SUbJECTS COMPARED WITH CURVES OBSERVED IN A PATIENT WITH RHEUMATOID ARTHRITIS BEFORE AND AFTER TREATMENT. (Curves labeled, respectively, "normal," "untreated," and "treated.") Hyaluronidase was injected after the measurement at zero time. 


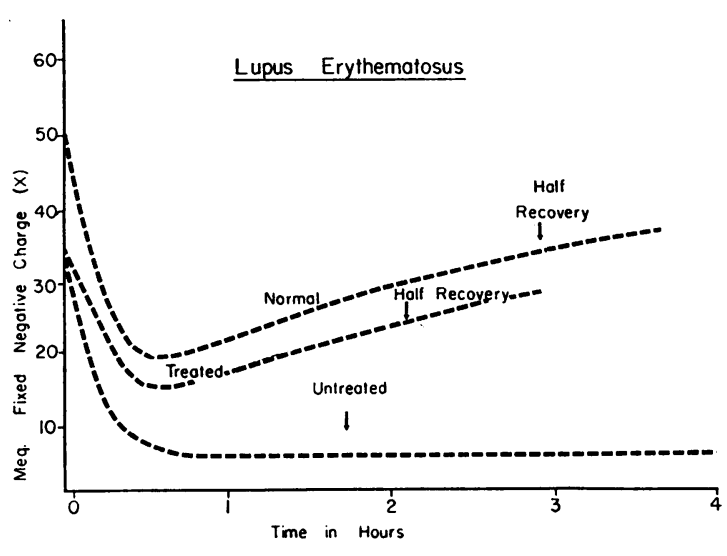

Fig. 4. Time-response curves for a patient with LUPUS ERYTHEMATOSUS BEFORE AND AFTER TREATMENT WITH 50 MG OF PREDNISONE DAILY FOR 10 WEEKS.

patients with systemic lupus erythematosus, and about $15 \mathrm{mEq}$ in patients with scleroderma and rheumatoid arthritis, as compared with the normal value of $50 \mathrm{mEq}$. After hyaluronidase injection, the value of $x$ fell to about $5 \mathrm{mEq}$ or less in all patients (Figures 3-6; Table I). This effect was observed in about 30 minutes. Usually no recovery was observed in any of the patients during study periods of up to 3.5 hours.

Cushing's syndrome. The connective tissue function test was also performed in three patients with Cushing's syndrome. The initial colloidal charge density was about $30 \mathrm{mEq}$, as compared with the normal level of 50 . After hyaluronidase the level fell to about $5 \mathrm{mEq}$ (Figure 6; Table I). Recovery was very rapid, however, and the initial negative charge was fully restored within 2 to 3 hours, while the half-recovery time was about 60 minutes.

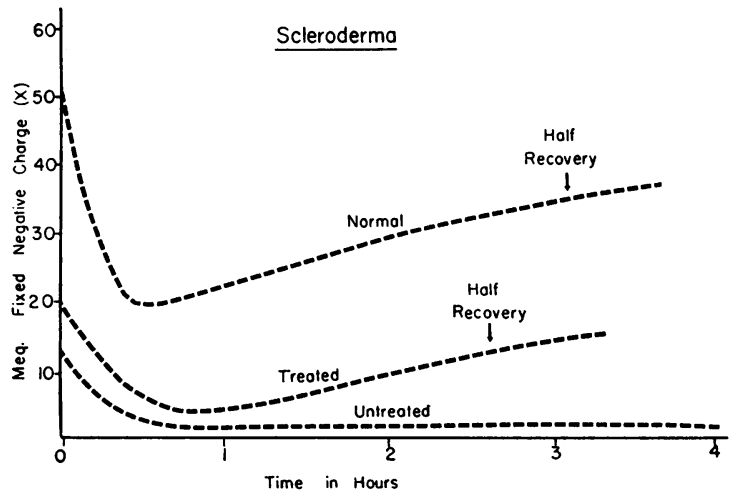

Fig. 5. Time-Response cUrves for a Patient With SCLERODERMA BEFORE AND AFTER TREATMENT WITH 20 MG PREDNISONE DAILY FOR 6 MONTHS.

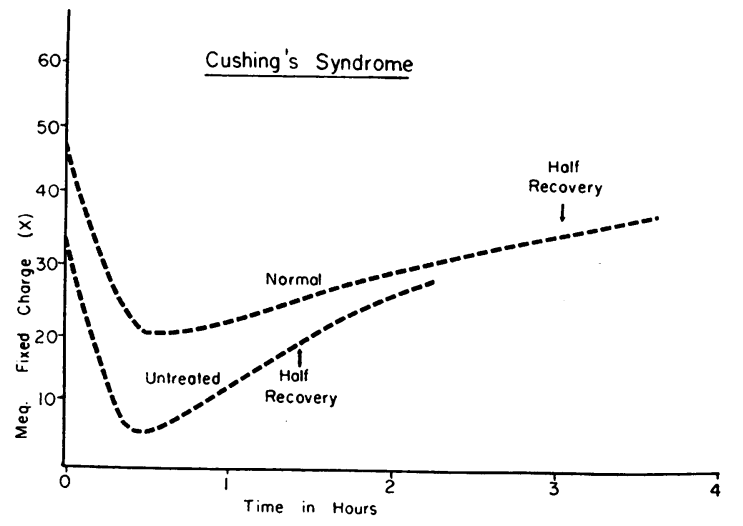

Fig. 6. Time-response curve for a patient with CUSHING'S SYNDROME COMPARED WITH THE CURVE FOR NORMAL SUBJECTS.

Effects of treatment. One patient with rheumatoid arthritis was restudied after 2 weeks of treatment with sodium salicylate $(600 \mathrm{mg}$ four times daily). The time-response curve is compared with that of the untreated group in Figure 3. Although the initial density of negative charge was slightly higher after therapy, the level was still considerably below the normal control level. Hyaluronidase produced only a slight change in this level, presumably due to the inhibitory effect of salicylate (19). No recovery was noted during the 3.5-hour observation period. The patient continued to receive salicylate for another week and was then retested 36 hours after discontinuation of treatment. The results at that time closely approximated the original curve observed previous to any treatment.

One patient with systemic lupus erythematosus was given prednisone ( $50 \mathrm{mg}$ daily) for 10 weeks before retesting. After this treatment the initial negative charge density was not significantly changed. The change after hyaluronidase remained greater than normal, but was less than in the untreated patients. The recovery curve paralleled the normal, but remained approximately 5 $\mathrm{mEq}$ lower throughout (Figure 4).

Three patients with scleroderma were restudied after 3 to 12 months of treatment with prednisone ( 20 to $25 \mathrm{mg}$ daily). The initial density of negative charge had increased by about $10 \mathrm{mEq}$. The change after hyaluronidase was slightly less than in the untreated cases, and some recovery was observed after the initial effect of the enzyme (Figure 5). 
One patient with Cushing's syndrome was reexamined approximately 8 months after treatment by bilateral adrenalectomy. At that time he was receiving $37.5 \mathrm{mg}$ of cortisone daily, and $25 \mathrm{mg}$ of deoxycorticosterone acetate per month, and was in good health. The initial density of negative charge of the dermal connective tissue was about $14 \mathrm{mEq}$ less than before surgery, and no recovery was observed during a 3.5-hour testing period after the action of hyaluronidase.

\section{DISCUSSION}

Attempts have been made from time to time to evaluate connective tissue changes in pathological states by investigating the spreading of various diffusible substances. One of the earliest methods, proposed by McClure and Aldrich $(20,21)$, measured the disappearance time of intradermal saline blebs. The results may be interpreted as reflecting indirectly the state of the tissue colloids, including their water-binding properties.

More recently several procedures using hyaluronidase and dyes have been described (2225 ). The spreading reaction appears to be very complex; it depends not only on the state of the tissue but also on the method of injection, the affinity of the tissue for the indicator, and the degree of irritation produced by the dye (13). Moreover the effect of recovery on the spreading reaction is difficult to delineate. For these reasons the interpretation of dye diffusion experiments may be equivocal. The colloidal state of the ground substance can be more directly studied by using the electrometric method outlined in this report. Kinetics of the response can be quantitatively followed. In this way the stages of breakdown and recovery are sharply defined.

In untreated patients a clear distinction between the various connective tissue diseases cannot be made on the basis of electrometric measurements. When the time-response curves are compared with the normal curve, however (Figures 3-5), three characteristics of these pathological conditions may be distinguished: 1) the initial colloidal charge density is lower in the patients with rheumatoid arthritis, scleroderma and systemic lupus erythematosus; 2) the colloidal charge density after hyaluronidase becomes very low $(5 \mathrm{mEq}$ or less) compared with that found in the healthy group under similar conditions (about $20 \mathrm{mEq}$ ); and 3 ) there is little or no reversal of the effect during the recovery period of 3 to 4 hours. $^{3}$ These findings suggest that in these disease states the ground substance of the dermal connective tissue differs from the normal both in composition and in responses. Changes in the hexosaminehydroxyproline ratios of dermal connective tissue in certain diseases support this interpretation (26). Reversal of the enzymatic breakdown appears to depend on both cellular and extracellular responses; synthesis of extracellular colloids would depend on cellular metabolism, whereas replacement by flow or hydrostatic pressure would depend primarily on the viscous properties of extracellular phases and components. In connective tissue diseases there appears to be a decrease in negatively charged colloidal components of the kind which are broken down by hyaluronidase (i.e., chondroitin sulfate and hyaluronic acid). Accompanying this change there is a marked decrease in the rate at which negatively charged components are replaced in a region in which they have been enzymatically hydrolyzed. The inhibited rate may result from impaired rheological properties as well as from failure of the cells to synthesize the necessary components. The halfrecovery time as determined electrometrically is much more rapid than results obtained by isotopic studies of hyaluronic acid (4 days) and chondroitin sulfuric acid (8 to 10 days) (27). Clinical and histological observations on wound repair, however, also indicate a more rapid recovery rate. In the electrometric studies the recovery is influenced by the flow of colloids from contiguous areas and by cellular synthesis of new materials. Fluidity seems to be enhanced in Cushing's syndrome or by administration of cortisone (14), and to be lowered in collagen diseases.

The results of therapy, particularly when the same drug was used, show that there are also characteristic differences between the various conditions. The time-response curve in the patient with systemic lupus erythematosus receiving prednisone approximated the normal curve fairly well, in contrast with the time-response curves of patients with scleroderma who were receiving similar treatment. This difference in response is in accordance with

${ }^{3}$ The possibility that changes in connective tissue state would be demonstrated in other kinds of illness is recognized but has not been tested. 
clinical experience. Electrometric changes do not, however, always parallel the clinical response to therapy. In the case of rheumatoid arthritis, for example, salicylates produced remission of symptoms with relatively small changes observed in the state of the tissue colloids, as measured by colloidal charge. It is evident that "clinically successful" treatment is not always synonymous with reversal of the pathological tissue changes.

Whereas under normal circumstances a compound such as cortisone retards repair, it promotes a remission of symptoms in many connective tissue diseases. The following explanation is suggested. Cortisone stimulates the connective tissuecells to form ground substance which differs qualitatively from the normal and which is characterized by a low density of negative colloidal charge (low cation binding). This has been demonstrated in electrometric studies on animals (14) and in the patients with Cushing's syndrome. In the normal subject the altered ground substance formed in response to cortisone interferes with proper healing. In the pathological state, however, the same modified ground substance represents a partial reversal of the disease process. In the healthy subject the modified ground substance is characterized by lowered negative charge and by increased fluidity; in pathological states cortisone may increase both the negative charge and the fluidity. Thus, depending on the initial state of reference, cortisone may promote either a partial degradation or a partial restoration of the connective tissue.

The adaptation of the electrometric method as a test of connective tissue function in patients has made it possible to characterize the state of the colloids, to describe some of the recuperative powers of the tissue, and to determine the response to drugs. Through in vivo studies of the physicochemical properties of connective tissue, valuable insights into its normal and pathological behavior may be gained.

\section{SUMMARY}

The rate at which connective tissue ground substance is disaggregated and restored after injection of hyaluronidase may be taken as an index of its initial state and its capacity for repair. This reaction was studied by an electrometric method involving the serial measurement of displaced
Donnan potentials in the dermis. Normal persons and patients with rheumatoid arthritis, scleroderma and systemic lupus erythematosus were compared. The results indicate that in these connective tissue diseases a ground substance is formed which differs both qualitatively and quantitatively from the normal. The rate of reconstitution after enzymatic action is markedly delayed. The administration of corticosteroids tends to reverse these conditions. The measurements of changes in the state of the ground substance after the injection of hyaluronidase is a useful test for evaluating connective tissue diseases and the effects of therapy.

\section{ACKNOWLEDGMENT}

The prednisone used to treat the patients reported was kindly supplied as Meticorten by the Schering Corporation, Bloomfield, N. J., through the courtesy of Dr. C. J. Szmal. The hyaluronidase (Wydase) was generously contributed by Wyeth and Co., through the courtesy of W. H. Rennie, Jr.

\section{REFERENCES}

1. Engel, M. B., Joseph, N. R., and Catchpole, H. R. Homeostasis of connective tissues. I. Calciumsodium equilibrium. A. M. A. Arch. Path. 1954, 58, 26.

2. Joseph, N. R., Engel, M. B., and Catchpole, H. R. Homeostasis of connective tissues. II. Potassiumsodium equilibrium. A. M. A. Arch. Path. 1954, 58, 40.

3. Catchpole, H. R., Joseph, N. R., and Engel, M. B. Homeostasis of connective tissues. III. Magnesiumsodium equilibrium and interactions with strontium and lead. A. M. A. Arch. Path. 1956, 61, 503.

4. Joseph, N. R., Engel, M. B., and Catchpole, H. R. Interaction of ions and connective tissue. Biochim. biophys. Acta 1952, 8, 575.

5. Joseph, N. R., Catchpole, H. R., Laskin, D. M., and Engel, M. B. Titration curves of colloidal surfaces. II. Connective tissues. Arch. Biochem. 1959, 84, 224.

6. Gersh, I., and Catchpole, H. R. The organization of ground substance and basement membrane and its significance in tissue injury, disease and growth Amer. J. Anat. 1949, 85, 457.

7. Gersh, I., and Catchpole, H. R. The nature of ground substance of connective tissue. Perspec. Biol. Med. 1960, 3, 282.

8. Bondareff, W. Submicroscopic morphology of connective tissue ground substance with particular regard to fibrillogenesis and aging. Gerontologia (Basel) 1957, 1, 222. 
9. Chase, W. H. Extracellular distribution of ferrocyanide in muscle. A. M. A. Arch. Path. 1959, 67, 525.

10. Dennis, J. B. Effects of various factors on the distribution of ferrocyanide in ground substance. A. M. A. Arch. Path. 1959, 67, 533.

11. Engel, M. B., Joseph, N. R., Laskin, D. M., and Catchpole, H. R. A theory of connective tissue behavior: Its implications in periodontal disease. Ann. N. Y. Acad. Sci. 1960, 85, 399.

12. Loeven, W. A. The complex binding between protein and mucopolysaccharide in connective tissue. Acta physiol. pharmacol. neerl. 1956, 5, 121.

13. Hechter, O. Mechanisms of spreading factor action. Ann. N. Y. Acad. Sci. 1950, 52, 1028.

14. Laskin, D. M., Engel, M. B., Joseph, N. R., and Corley, R. Effects of hyaluronidase and cortisone on connective tissue studied electrometrically. Proc. Soc. exp. Biol. (N. Y.) 1957, 94, 749.

15. Joseph, N. R., and Bourlière, F. Electrochemical changes in rat connective tissues with age. Experientia (Basel) 1956, suppl. 4, 44.

16. Bourlière, F., Joseph, N. R., and Molimard, R. Ageing of skin. 2. Adaptive responses in rat dermis in relation to age and growth. Gerontologia (Basel) 1957, 1, 163.

17. Joseph, N. R., and Engel, M. B. Titration curves of colloidal surfaces. I. Human epidermis. Arch. Biochem. 1959, 85, 209.

18. Engel, M. B., and Joseph, N. R. Titration curves of colloidal surfaces. III. Wool. Arch. Biochem. 1960, 86, 117.

19. Guerra, F. Hyaluronidase inhibition by sodium salicylate in rheumatic fever. Science 1946, 103, 686.
20. McClure, W. B., and Aldrich, C. A. Time required for disappearance of intradermally injected salt solution. J. Amer. med. Ass. 1923, 81, 293.

21. Aldrich, C. A., and McClure, W. B. The intradermal salt solution tests; its prognostic value in "nephritis" with generalized edema. J. Amer. med. Ass. 1924, 82, 1425.

22. Holborow, E. J., and Keech, M. K. Hyaluronidase skin spreading effect; an analysis of repeated measurements. Brit. med. J. 1951, 2, 1173.

23. Bywaters, E. G. L., Holborow, E. J., and Keech, M. K. Reconstitution of the dermal barrier to dye spread after hyaluronidase injection. Brit. med. J. 1951, 2, 1178.

24. Mahaux, J., and Stienlet, R. Le test de dispersion hyaluronidase. Indicateur coloré au cours du traitement de l'arthrite rhumatoïde et du lupus érythémateux par la corticotrophine et par la cortisone. Ann. Endocr. (Paris) 1951, 12, 1104.

25. Mahaux, J. Le test de dispersion hyaluronidase hémoglobine dans la fièvre rheumatismale aiguë et dans l'arthrite rhumatoïde traitées ou non par la corticotrophine hypophysaire. Acta clin. belg. 1952, 7, 338.

26. Wright, E. T., Sobel, H., and Nelson, N. H. Hexosamine-collagen ratio of skin biopsies in patients receiving systemic corticosteroids. Proc. Soc. exp. Biol. (N. Y.) 1960, 103, 117.

27. Schiller, S., Mathews, M. B., Cifonelli, J. A., and Dorfman, A. The metabolism of mucopolysaccharides in animals. III. Further studies on skin utilizing C14-glucose, C14-acetate, and S35- sodium sulfate. J. biol. Chem. 1956, 218, 139.

\section{SPECIAL NOTICE TO SUBSCRIBERS}

Post Offices will no longer forward the Journal when you move. Please notify The Journal of Clinical Investigation, Business Office, 333 Cedar Street, New Haven 11, Conn., at once when you have a change of address, and do not omit the zone number if there is one. 